\title{
LUZIA, A TEINIAGUÁ DE SANTA FÉ
}

\author{
Gínia Maria Gomes
}

RESUMO: This essay consists of an intertextual analysis between Luzia - O tempo e $o$ vento - and the lendary teiniaguá - A Salamanca do Jarau. Erico Veríssimo refers himself to Simões Lopes Neto's narrative when he nominates "The teiniaguá" the chapter in which Luzia is the main character. This study will try to track some of the features that approaches both characters. Among them we can detach the origin, the physical aspect and the kind of relationship they have with men.

PALAVRAS-CHAVE: Intertextualidade, teiniaguá, olhar, domínio.

A lenda da teiniaguá aparece nitidamente representada em $O$ Continente. Sem qualquer tentativa de encobrimento, as relações intertextuais estão desveladas desde o início. É assim que, ao reportar-se à lenda apresentada no conto de Simões Lopes Neto, A Salamanca do Jarau, Erico Verissimo imediatamente a evidencia ao intitular "A teiniaguá" o capítulo em que Luzia se destaca como a personagem nuclear da narrativa. A referência à lenda é incontestável e o próprio autor se encarrega de conferir-lhe tal destaque. Se a relação intertextual é exposta sem subterfúgios, a configuração da personagem Luzia segue o mesmo caminho, ou seja, os seus traços marcantes remetem à teiniaguá lendária, o que é representado no texto com a máxima clareza, principalmente por Winter, um dos focos através do qual ela é observada. Entre os traços marcantes que aproximam as duas personagens destacam-se a origem, o aspecto físico e o caráter devorador da relação que elas mantêm com os homens.

Em A Salamanca do Jarau, a princesa moura fora trazida de terras distantes pelos espanhóis; transformada pelo demônio em teiniaguá, dele aprendera os segredos dos tesouros da furna. Estes dois aspectos são encontrados na trajetória de Luzia: ela é oriunda da Corte e é "herdeira de uma das maiores fortunas de Santa Fé" (SCHÜLER, 1972, p. 168). As duas pertencem a um espaço completamente diferente daquele para o qual são transportadas; disto decorre a rejeição a que são submetidas: a teiniaguá lendária por parte dos padres missionários, enquanto Luzia por parte dos santa-fezenses que, devido aos seus hábitos diferentes, passam a vê-la como "mulher perdida" (VERISSIMO, 1987, p. 335). Por outro lado, a riqueza a que ambas estão associadas, determina que se transformem em objeto de cobiça por parte dos homens.

Gínia Maria Gomes é professora de Literatura Brasileira da UFRGS. 
No que concerne à personagem de Erico, Bibiana põe em segundo plano o fato de Luzia não corresponder ao ideal de mulher, para deixar falar apenas os atributos materiais, que suplantam os perigos que a "forasteira" possa trazer.

A teiniaguá lendária é capturada pelo sacristão ao sair da lagoa. O seu habitat sendo a água, ao vê-la encaminhar-se em sua direção, ele imediatamente pensa: "pois que da água saía, é que na água viveria" (LOPES NETO, 1978, p. 141); é então que procura uma guampa e a enche de água para aí aprisionar a teiniaguá. A aproximação com Luzia está manifesta no seu fascínio pelo mar - que se situa na razão inversa de seu ódio pelo campo, por aquela terra tão distante do mar. Em um de seus diálogos com o filho ela tenta mostrar-lhe a beleza do mar e fica perplexa diante de sua falta de curiosidade em conhecê-lo.

As marcas da teiniaguá lendária são mais contundentes ao se considerar os traços físicos. Na cerimônia do enforcamento de Severino, o médico se detém no "brilhante" refulgente na cabeça de Luzia, o que a assemelha à personagem simoniana, cuja cabeça é constituída pelo medalhão transformado em pedra que, por ter recebido a primeira luz do dia, "ficou vermelho como brasa e tão brilhante que os olhos de gente vivente não podiam parar nela, ficando encandeados, quase cegos!..." (LOPES NETO, 1978, p. 138). O trecho destaca duas características da teiniaguá lendária: o aspecto físico da personagem, em que se sobressai o brilho, e a reação dos outros que, impossibilitados de confrontá-la, correm o risco de serem destruídos - "quase cegos". Na personagem de Erico o brilho da cabeça é apresentado pelo "brilhante" que a adorna; por outro lado, também em relação à Luzia, o caráter de destruição está presente, embora implícito, na medida em que os homens tentam fugir ao seu olhar.

É importante aprofundar a questão dos olhos, que nas duas personagens destaca-se como um dos elementos essenciais, pois é através deles que se evidencia a dominação. O sacristão, diante da jovem princesa moura, tem como primeiro intuito defender-se por meio do crucifixo; porém, ao levantá-lo à altura dos olhos, ele sucumbe, completamente dominado": "E aí parou, porque os olhos de amor, tão soberanos e cativos, em mil vidas de homens outros se não viram!..." (LOPES NETO, 1978, p. 151)

No texto de Simões Lopes Neto são, pois, os olhos/olhar que submetem o sacristão. Esta circunstância está de acordo com o simbolismo do olhar:

"O olhar é carregado de todas as paixões da alma e dotado de um poder mágico que lhe confere uma terrível eficácia. O olhar é o instrumento das ordens interiores: ele mata, fascina, seduz, assim como exprime." (CHEVALIER, GHEERBRANT, 1989, p. 653)

Em A Salamanca, eles aparecem desdobrados na expressão "carbúnculo" usada para representar a teiniaguá. Chevalier e Gheerbrant, ao fazerem referência a esta pedra, a associam aos olhos:

"Mencionada como capaz de brilhar nas trevas. Era incrustada nas órbitas

\footnotetext{
1"A sedução dos olhos. A mais imediata, a mais pura. A que prescinde de palavras; só os olhares enredamse numa espécie de duelo, de enlaçamento imediato, à revelia dos outros e de seus discursos: discreto fascínio de um orgasmo imóvel e silencioso.” BAUDRILLARD, 1991, p. 87.
} 
de estátuas, simbolizando o brilho nos olhos, testemunha da intensidade da vida e do desejo. Quando colocada ao longo de um corredor escuro para guiar o caminho, simboliza, mais precisamente, os olhos que vêem na noite, ou o desejo que espicaçava a busca de seu objeto." (CHEVALIER, GHEERBRANT, 1989, p. 36)

Nestas observações, se "carbúnculo" está relacionado a olhar, também o está à luz. Segundo Durand, esta representa um deslocamento do olho/olhar: "é normal que o olho, órgão da vista, seja associado ao objeto da visão, ou seja, à luz" (DURAND, 1989, p. 106) Ora, a luminosidade revela-se um atributo muito forte da teiniaguá lendária: à sua cabeça está a pedra brilhante, que não pode ser confrontada. Este fato parece confirmar-se no primeiro encontro com o sacristão:

"e quando eu estava na beira da água, vendo o que estava vendo, então rompeu dela um clarão, maior que o da luz a pino do dia, clarão vermelho, como dum sol morrente, e que luzia desde o fundão da lagoa e varava a água barrenta...” (LOPES NETO, 1978, p. 144)

Também na personagem de Verissimo o olhar assume um plano de destaque. Ele já está indiciado em seu nome: Luzia é a santa protetora dos olhos. Além desta circunstância há a explícita referência à luz, luzir, brilhar, que ele comporta. O nome propicia a nítida alusão à personagem lendária, em que a luz surge como um componente do aspecto físico. Esta questão, em Luzia, tem um aspecto novo: a cegueira da santa. Nas diferentes mitologias o cego é aquele que vê:

"o cego é aquele que ignora as aparências enganadoras do mundo e, graças a isso, tem o privilégio de conhecer sua realidade secreta, profunda, proibida ao comum dos mortais. O cego participa do divino, é o inspirado, o poeta, o taumaturgo, o vidente." (CHEVALIER, GHEERBRANT, 1989, p. 217)

Na mitologia grega, é principalmente Tirésias quem desempenha esta função: em busca de informações sobre seu futuro, Ulisses vai ao Hades para se comunicar com ele (HOMERO, 1979, p. 102-103). No contexto de Santa Fé, Luzia parece cumprir este papel: ela vê aquilo que aos demais é vedado. O seu olhar perscruta a escuridão que a circunda.

$\mathrm{Na}$ personagem de Erico, além do nome, a questão é retomada nas referências explícitas a seus olhos, quando são utilizados termos que claramente aludem à teiniaguá lendária:

"Ela tem olhos de mulher falsa..." (VERISSIMO, 1987, p.336)

"(Luzia Silva devia ter mandinga naqueles olhos de réptil.)" (VERISSIMO, 1987, p.359)

As expressões "mulher falsa", "mandinga" e "olhos de réptil", ao porem em foco a personagem lendária, oportunizam a percepção do valor assumido pelos olhos, que representam o instrumento do domínio. Este transparece principalmente em relação ao noivo que, numa atitude contrária à do macho, sempre condicionado pelo código de honra, vê-se indefeso diante de seu olhar:

"Bolívar não pode suportar o olhar da noiva. Baixou os olhos para o chão." (VERISSIMO, 1987, p. 375) 
"Não podia resistir ao olhar dela: dava-lhe um acanhamento que ele nunca sentira diante de mulher alguma." (VERISSIMO,1987, p. 376)

A atitude de Bolívar repete-se com o juiz, que "fechou os olhos" para não ceder às suas idéias, e com Florêncio, que evita o confronto. Winter, que também não fica imune ao fascínio de Luzia, tem uma reação diferente, pois não procura a fuga, ao contrário, não a perde de vista, porém com a consciência da possibilidade de ser vencido e, ao lembrar-se da lenda, imagina-se dominado: "Winter pensou no sacristão da lenda e viu a lagartixa encantada enroscar-se nele." (VERISSIMO,1987, p. 381)

As observações permitem afirmar que tanto a teiniaguá lendária quanto Luzia têm nos olhos o instrumento a partir do qual exercem o domínio sobre os homens, fazendo-os sucumbir. No texto de Erico Verissimo esse elemento acentua-se pela incidência de olhos/olhar que se sobressai na festa do noivado/enforcamento. Assim, a principal comunicação que se realiza entre os presentes se dá através do olhar. Os múltiplos olhares flagrados na cerimônia podem ser apreendidos sob várias nuanças que os diferenciam. Sem a pretensão de esgotar a problemática, salienta-se apenas aqueles que mais se sobressaem: os relacionados à percepção do "real fora de nós" e aqueles representativos do "cuidar, zelar, guardar, ações que trazem o outro para a esfera do sujeito" (BOSI, 1988, p. 78). No que concerne ao olhar que busca "perceber o real" (BOSI, 1988, p. 78),.destaca-se o Dr. Winter, sempre perscrutando o que se desenrola a sua volta. À afirmação de Luzia "Negro não é gente" (VERISSIMO,1987, p. 378), o médico tira os óculos para limpá-los, deixando transparente que o ver é determinante do compreender. É, talvez, na busca de compreensão da "rapariga singular" (VERISSIMO,1987, p. 381) representada por Luzia, que seu olhar está constantemente direcionado para ela, a quem procura estar atento. Este fato culmina na hora do enforcamento: ele olha para Luzia que olha para Severino, e vê toda a cerimônia por meio das reações que procura detectar em seu rosto, cujos olhos estão fixos na forca. $\mathrm{Na}$ outra acepção, destaca-se o olhar zeloso de Bibiana para o filho. Por perceber a ansiedade de Bolívar, ela continuamente volta-se para ele:

"Bibiana olhava apreensiva para o filho" (VERISSIMO,1987, p.377)

"Mas D. Bibiana estava com a atenção no filho". (VERISSIMO,1987, p.381)

Situa-se no mesmo prisma de cuidado e zelo o olhar de Florêncio para o primo: "Florêncio estava sentado na ponta da cadeira, com os olhos postos no primo, temendo que ele fizesse ou dissesse alguma coisa inconveniente." (VERISSIMO,1987, p. 382)

Ao lado destes olhares também se destaca o olhar de ansiedade. No caso, se sobressaem os olhares de Bolívar e de Aguinaldo. O de Bolívar é sintomático de sua culpa e desespero diante do enforcamento do amigo:

"Seus olhos de instante a instante voltavam-se para a janela, mesmo contra a sua vontade." (VERISSIMO,1987, p. 372)

"Bolívar tornou a olhar para o relógio mas não pôde distinguir o mostrador, porque o suor lhe entrara pelos olhos e lhe turvava a visão." (VERISSIMO,1987, p.375) 
O rapaz se mostra apreensivo com a proximidade da hora do enforcamento, fazendo com que a inquietação não lhe permita sequer "distinguir o mostrador". Sob um prisma similar de ansiedade, mas com um conteúdo em tudo diverso, situa-se o olhar de Aguinaldo. Para ele, a aproximação da hora representa o prazer que o enforcamento poderá proporcionar-lhe, daí a alegria incontida que deixa transparecer:

"Aguinaldo tirou do bolso o relógio e olhou para o mostrador.

- $\quad$ Faltam quinze minutos.” (VERISSIMO,1987, p. 381)

"Aguinaldo aproximou-se da janela, relanceou os olhos pela praça e disse:

- $\quad$ Está assim de gente. Parece até quermesse.” (VERISSIMO,1987, p. 382)

A problemática do olhar, desdobrada através dos diferentes olhares que se concretizam entre os presentes no sobrado, constitui-se em um aspecto relevante no diálogo intertextual. A análise dos múltiplos olhares, além de reforçar a questão fundamental - a importância do olhar de Luzia como instrumento de dominação, o que propicia a abordagem sob o prisma da intertextualidade - mostra a necessidade imperiosa de fazer convergir a discussão neste sentido, na tentativa de traduzir o seu conteúdo. Antes de aprofundar a reflexão sobre os sentimentos mais intensos que seu olhar deixa transparecer, convém fazer referência ao objeto para o qual se volta, fazendo-o seduzido. Na trajetória da personagem, esse papel é preenchido pela morte, a cujo fascínio prazerosamente sucumbe. É interessante notar que, nas principais cenas em que Luzia está envolvida, a morte ocupa um lugar relevante. Esse é o caso do noivado/enforcamento, a que se reportou antes; o mesmo ocorre com a morte do avô, a peste em Porto Alegre e a doença que a condena. Todas essa situações atraem a personagem, que é vista a partir de um prisma exterior: ou de Winter ou de Bolívar.

A cena do noivado/enforcamento é muito expressiva para se tentar compreender o olhar de Luzia, fazendo-se, inclusive, paradigmática das outras, pois nela a interpretação do médico indicia algumas reflexões que poderão ser estendidas às demais. O Dr. Winter, que vê o enforcamento de Severino olhando para Luzia, observa que sua expressão se vai transformando no transcorrer da cerimônia: os olhos sempre fixos na forca, sua expressão passa "de profundo interesse" para uma "máscara de gozo que parece chegar quase ao orgasmo" (VERISSIMO, 1987, p.384). A avaliação do médico permite atentar para o forte componente do sentir que há no olhar da personagem, a que o próprio Winter dá uma conotação negativa, pois, ao identificá-lo como um sentimento prazeroso, fica "estarrecido" (VERISSIMO,1987, p. 384).

A interpretação do médico, ao pôr em foco o olhar diante da morte e o sentimento de gozo próximo ao orgasmo vivenciado pela personagem, oportuniza a reflexão sobre a associação amor/morte, problemática recorrente na arte a partir do século XVI, porém já presente no pensamento mítico. Para Cambell, a morte aparece associada ao sexo em diferentes mitologias, o que é muito bem representado quando um deus ocupa simultaneamente a dupla função:

"um após outro você descobre esses deuses que presidem, ao mesmo tempo, à morte e às geração. $\mathrm{O}$ deus da morte, Guede, na tradição vudu haitiana, é também o deus do sexo. O deus egípcio Osíris era o juiz e o senhor dos mortos e o senhor da regeneração da vida. É um tema básico - aquele que 
morre, nasce. É preciso haver morte para que haja vida.” (CAMPBELL, 1990, p. 116)

Também Philippe Ariès reflete sobre a estreita vinculação que se estabelece entre amor/morte. Entre as expressões artísticas que o autor toma como base para discutir a problemática, convém destacar as danças macabras, pois no século XVI passam a ser impregnadas de um conteúdo violento e erótico, que antes não comportavam: “A morte já não é o instrumento da necessidade; está animada por um desejo de fruição, sendo ao mesmo tempo morte e volúpia” (ARIÈS, 1990, p. 403). Ao discorrer sobre algumas pinturas, Ariès mostra o caráter sádico que a relação amor/ morte assume ao longo dos séculos, até apresentar-se francamente descoberta nos séculos XVIII e XIX.

A cena do noivado/enforcamento comporta os sentimentos antagônicos presentes na relação amor/morte; eles já se evidenciam no fato de os santa-fezenses acorrerem à praça para assisti-la, o que significa que estão vivendo em um clima de festa, o que é muito bem captado por Aguinaldo, quando afirma "Parece até quermesse". É, no entanto, o olhar de Luzia para o sofrimento e morte de Severino que, ao evidenciar o seu prazer diante de tal circunstância, põe a descoberto a estreita vinculação entre amor/morte, que vem à luz através dos sentimentos sádicos que são percebidos na expressão da personagem.

O olhar voluptuoso diante da morte, por cujo fascínio se deixa envolver, bem como o domínio sobre os homens, marca inconfundível da teiniaguá lendária e de Luzia, cujos olhos representam a força avassaladora que submete aqueles que ousam afrontá-las, tem no erotismo o seu ponto de ancoragem. É em decorrência deste erotismo que aqueles que delas se aproximam tornam-se vítimas e, sujeitandose aos encantos irresistíveis da "fêmea devoradora" 2 , são arrastados na voragem erótica em que se perdem.

A teiniaguá lendária tem na beleza a manifestação primeira de seu erotismo. Aprisionada na guampa como lagartixa com cabeça de pedra, transforma-se na moça extraordinariamente bela, conforme as palavras do sacristão o atestam: "Bonita, linda, bela, na minha frente estava uma moça!...” (LOPES NETO, 1978, p. 143) Esta beleza é reforçada pela própria princesa moura, consciente de seus atributos: "Sou jovem... sou formosa... o meu corpo é rijo e não tocado!"” (SJ, p.144) A sua fala denuncia a importância do corpo - jovem, belo, rijo - já antecipando a sexualidade, base de seu relacionamento com a sacristão, que terá seu ápice na orgia regada a vinho, causa de sua perda, pois que, descoberto pelos padres, é condenado à morte.

No primeiro confronto o sacristão parece inclinado a seguir as normas ditadas pela igreja, porque se apega ao rosário para afrontá-la, porém, sem conseguir vencêla, é dominado por seu olhar. Então se inicia o conluio amoroso que ocupa suas noites: "Cada noite era meu ninho o regaço da moura, mas, quando batia a alva, ela

${ }^{2}$ É o crítico Flávio Loureiro Chaves quem percebe o caráter devorador de Luzia: "Uma fêmea devoradora onde se misturam o sexo e a violência, que atrai o macho, como a teiniaguá lendária, e imediatamente o aniquila". (CHAVES, 1981, p. 77)

176 
desaparecia ante a minha face cavada de olheiras... (LOPES NETO, 1978, p. 145)

Acedendo ao desejo da teiniaguá de "misturar o mel do seu sustento com o vinho do santo sacrifício", o sacristão acorre ao altar e lhe traz "o copo de ouro consagrado" (LOPES NETO, 1978, p. 145) transbordando de vinho. Bêbado, não toma as devidas precauções e, ao despertar, o seu destino está selado: descoberto pelos padres, a "morte do garrote" (LOPES NETO, 1978, p.146) o espera. No entanto, mesmo com a proximidade da morte, o carrasco a postos, o seu pensamento o afasta da realidade circundante e se concentra na teiniaguá. Todos os seus sentidos se direcionam para a mulher sedutora diante de quem sucumbiu ${ }^{3}$. Este fato se comprova por meio de sua lembrança, permeada pelo erotismo que constituía a base deste relacionamento. É assim que vê os seus olhos "soberanos e cativos" e a "tentação do riso mimoso", ouve o seu "chamado carinhoso", sente o aroma das "flores de mel fino de que a teiniaguá tanto gostava", saboreia os "seus beijos", (LOPES NETO, 1978, p. 149) "o "tato (...) roçava sôfrego pelo corpo da encantada, torneado e rijo, que se encolhia em ânsias, arrepiado como um lombo de jaguar no cio, que se estendia planchado como um corpo de cascavel em fúria..." (LOPES NETO, 1978, p. 150) A memória registra o erotismo que se evola da teiniaguá, a tal ponto que a lembrança dos momentos compensam a morte que ele está prestes a enfrentar. A teiniaguá é a única realidade que consegue divisar, pois sequer a salvação cristã tem importância: "tanto como as gentes, lá, iam acabando as orações para alcançar a clemência divina, ia eu começando o meu fadário, todo dado à teiniaguá, que me enfeitiçou de amor, pelo seu amor de princesa moura, pelo seu amor de mulher, que vale mais que destino de homem!...” (LOPES NETO, 1978, p. 150)

O erotismo da teiniaguá que, enfeitiçando o sacristão determina seu fim, propicia o desdobramento da problemática, abrindo-a para a abordagem sob o enfoque da devoração. Roger Caillois analisa o comportamento do louva-a-deus, cuja fêmea devora o macho durante ou depois da cópula. Ressalta que a devoração presenciada na natureza dá margem à criações imaginárias que reproduzem a observação verificada no comportamento do louva-a-deus: "É assim que os antigos consideravam que, movida pela doçura da volúpia, a fêmea víbora comia a cabeça do macho durante a cópula" (CAILLOIS, 1972, p. 44). Afirma, também, "que subsistem no homem traços notáveis desse parentesco, ou convergência de instintos" como a "dentada de amor" (CAILLOIS, 1972, p. 46) na realização do coito. Também situa-se na perspectiva da devoração, o medo da castração, que tem "por origem o temor da vagina dentada"; este, na realidade, aponta para o "medo do macho de ser devorado pela fêmea durante ou após o coito" (CAILLOIS, 1972, p. 47). O estudioso salienta que inúmeros mitos e lendas representam essa devoração. No caso, são " criatura demoníacas que, sob a aparência de mulheres de uma grande beleza, atraem os jovens, através de carícias, para em seguida se alimentarem de sua carne" (CAILLOIS, 1972, p.48).

Admitindo-se a hipótese de Caillois, de que a sexualidade se encontra forte-

3"Ser seduzido é ser desviado de sua verdade. Seduzir é desviar os outros de sua verdade". BAUDRILLARD, 1991, p. 87. 
mente vinculada à alimentação, talvez esteja no fato de a teiniaguá ter sido alimentada com mel antes do coito que a efetiva devoração não se tenha concretizado, conforme ocorre em algumas lendas. Chevalier e Gheerbrant notam que o simbolismo do mel, em alguns textos sagrados, "adquire uma conotação erótica" (CHEVALIER, GHEERBRANT, 1989, p. 603). No texto simoniano a devoração é representada pelo comportamento da teiniaguá que, ao seduzir o sacristão, o faz seu escravo - ele passa a satisfazer seus desejos, mesmo quando estes se contrapõem ao mundo cristão em que estava inserido, como é o caso do episódio relativo ao vinho sacrossanto - levando-o à sujeição absoluta de seu feitiço. Permanecer vivo, aqui, não representa redenção ${ }^{4}$. Uma morte mais dolorosa lhe é imposta: o isolamento do mundo dos homens e a inserção no mundo do encantamento - simbólico de uma forma de morte, que não lhe permite o gozo das riquezas entre os homens e que o transforma em um ser triste.

O erotismo, que tem na devoração a sua principal característica, também pode ser percebido através da relação "mulher/bicho imundo" que se repete na fala do sacristão. O crítico Flávio Loureiro Chaves vê na expressão o feminino sendo representado "enquanto imagem do abismo e da desordem". O crítico ainda reforça: "A mulher/demônio associada ao Anhangá-Pitã; a mulher/moura que se vota à destruição da cristandade; a mulher/abismo capaz de provocar a subversão dos sentidos naturais; a mulher/bicho imundo cuja lembrança é já indissociável das conotações de falsidade, traição e feitiço" (CHAVES, 1982, p. 92). A fala do sacristão é decisiva ao reforçar os motivos de sua morte: por ter dado passo errado com bicho imundo, que era bicho e mulher moura, falsa, sedutora e feiticeira" (LOPES NETO, 1978, p. 146). São esses atributos da teiniaguá, explícitos na narrativa do sacristão - "falsidade", "traição" e "feitiço" - que permitem inscrevê-la na galeria de personagens que, em diferentes narrativas, objetivam a destruição do macho e possibilitam chamá-la de "fêmea devoradora".

Também a personagem de Erico Verissimo tem o erotismo/devoração como atributo que se apresenta em plano de evidência, distinguindo-a das demais mulheres e fazendo-a temida pelos homens, que dela se afastam com a justificativa: "Não nasci para corno" (VERISSIMO,1987, p. 335). Aqueles que permanecem a seu lado são atingidos pelo seu fascínio. Vê-se Bolívar, Florêncio, Winter e o Major tornarem-se suas vítimas, para sempre presos a esta mulher que, mesmo à morte, não perde seu feitiço. Ao filho não passa despercebido esse caráter devorador/destruidor da mãe, a quem relaciona às cantigas que ouve dos gaúchos.

É importante lembrar que Luzia, logo que chega à Santa Fé, sugere a impressão de "mulher perdida" (VERISSIMO,1987, p. 335); esta expressão relaciona-se às mulheres que vendem o corpo, o objeto da sedução. $\mathrm{O}$ erotismo é, pois, inerente à expressão e, ao relacionar-se à Luzia, dá indício do temor que aqueles homens têm de tal mulher, em tudo diferente das mulheres passivas de Santa Fé. Na realidade, eles vêem nela o risco de serem "cornos", o que motiva a fuga a sua sedução, porque

4"A Salamanca do Jarau, em seus dois motivos essenciais, contém uma apologia da renúncia cristã e da redenção pelo amor; é claro que apenas de modo implícito”. MEYER, 1986, p. 581.

178 
sabem da possibilidade de serem "devorados", situação a que não desejam se submeter. Apenas Bolívar e Florêncio persistem no assédio à forasteira, que Bibiana observa sob o prisma da sexualidade:

"E quando Luzia chegou da Corte e os meninos começaram a andar atrás dela como cachorrinhos assanhados ao redor duma cadela, seu primeiro ímpeto foi o de levar Boli para longe, a fim de evitar que ele se apaixonasse pela forasteira." (VERISSIMO,1987, p. 367)

Bibiana reconhece a força da nora, do que decorre a necessidade de o filho vir a dominá-la pois, isto não ocorrendo, poderá representar a perda: "Bolívar precisa domar essa potranca no primeiro dia do casamento, senão está perdido." (VERISSIMO,1987, p. 374)

As metáforas "cadela" e "potranca", utilizadas por Bibiana, permitem a recorrência à personagem lendária: mulher representada como "bicho imundo". A associação com o mundo animal destaca com especial ênfase o caráter primitivo da força avassaladora da fêmea que atrai o macho para perdê-lo. "Cachorrinhos ao redor de uma cadela" e "domar essa potranca" indiciam o erotismo da fêmea dominadora a quem o macho sucumbe. As suas observações mostram a percepção do poder sedutor de Luzia e, por isso mesmo, o perigo a que o filho estava se expondo. Erotismo/ devoração estão nitidamente representados, embora sob um enfoque negativo, o que é percebido desde o início, quando Bibiana pensa em levar o filho para longe.

As apreensões de Bibiana tornam-se realidade: o filho acaba sendo completamente dominado pela noiva. No entanto, é importante ressaltar a especificidade de seus sentimentos, porquanto erotismo/devoração aparecem associados à morte. A cerimônia do noivado/enforcamento de Severino é significativa. Nesta circunstância, Bolívar revela sentimentos contraditórios: de um lado, a ansiedade devido a proximidade da morte do amigo, pela qual se sente responsável, e de outro, a atração pela noiva, cuja voz o afeta. A realização simultânea dos dois eventos desencadeiam na personagem sentimentos que se alternam, ora tendo como foco Severino, ora Luzia. Assim sendo, a forte atração que sente pela noiva se intercambia com o sentimento de culpa, que tem seu ápice quando a sua inquietude chega ao paroxismo de mesclá-los, formando um todo indissolúvel:

"Mas o que era mesmo que ele temia? A hora do enforcamento? A hora do noivado? O suor agora lhe entrava pelos cantos da boca, pelos olhos, e por alguns segundos ele viu a noite através duma cortina líquida: tudo trêmulo e vago. Seus próprios pensamentos pareciam encharcados de suor, estavam confusos, misturados, eram como um mingau quente de febre. Pensava estonteadamente em Severino e em Luzia: ora lhe parecia que fora Luzia quem mandara matar Severino; ora era Severino quem estava na cama com Luzia, montado nela, com seus braços negros a enlaçarlhe as coxas, ora era Luzia quem estava na cadeia e ia ser enforcada." (VERISSIMO,1987, p. 348)

No trecho, erotismo e morte são denunciados por meio da atração sexual e da culpa, sintomática do estado em que Bolívar se encontrava. Tal é o nervosismo do 
rapaz, que os dois focos diretores de seus pensamentos e sentimentos - Luzia e Severino -, inicialmente claramente delineados, são invertidos e distorcidos para evidenciar os elementos básicos que os norteiam: erotismo e morte. Apresentando-se como a dupla face de Jano, se esclarecedores do momento ambíguo que a personagem estava vivendo, também caracterizam a maneira específica da irrupção da sexualidade. É assim que a morte se apresenta como um componente do erotismo; apesar da atração sexual - erotismo - e culpa - morte - retratarem realidades diversas, o amálgama que sofrem na fantasia do rapaz, demonstra ser este um aspecto relevante, que faz ressaltar a sua peculiaridade.

Embora o processo de simbiose que a relação erotismo/morte sofre na fantasia de Bolívar seja único no texto, esta vinculação não deixará de estar representada, ainda que de maneira diversa. Nos momentos em que a morte está próxima - enforcamento de Severino e peste em Porto Alegre -, a atração sexual se impõe com maior vigor. Ao longo da cerimônia do noivado, a preocupação de Bolívar volta-se para a realização do enforcamento. À aproximação da hora fatídica, o seu nervosismo aumenta, não conseguindo sequer divisar os ponteiros para saber as horas, tal o estado emocional em que se encontra, o que não passa despercebido para Luzia. Ao inquirilo, a voz da noiva o afeta, fazendo-o concentrar-se na excitação que lhe produz, "como se o estivesse convidando a ir para a cama" (VERISSIMO, 1987, p. 376). A atração quase irresistível desencadeada por sua voz atesta o fascínio inexplicável, de que o rapaz se mostra consciente:

"Bolívar nunca conseguiu explicar a si mesmo porque ficava tão excitado quando a noiva falava. Aquela voz tinha feitiço, punha-lhe uns arrepios no corpo. Quando a ouvia, ele tinha ímpetos de saltar sobre Luzia, rasgar-lhe as roupas e amá-la com fúria.” (VERISSIMO, 1987, p.372 )

O erotismo, signo da dominação de Luzia sobre Bolívar, tem como agravante a possibilidade de destruição, percebida desde o início por Florêncio, que manifesta seus temores ao refletir sobre o próximo noivado. Naturalmente ele avalia a situação de acordo com o código social vigente, em que a mulher deve ser dominada e o homem tem como ponto de honra ser o dominador; no caso de haver a inversão dos valores estabelecidos, o homem está perdido:

"No fundo ele se sentia feliz por Luzia não o ter escolhido. Feliz não era bem a palavra: aliviado, isso sim. Luzia não era mulher para ele nem para Bolívar. Ia casar com o rapaz por capricho ou por birra, ninguém sabia bem ao certo por quê. Amor não era, que Luzia não era mulher para isso. Pobre do Boli! Se não botasse cabresto na esposa desde o primeiro dia, estava perdido. Luzia era como certos cavalos que precisavam de rédea curta. Mas qual! Boli estava cego de amor, ia passar a vida dominado por ela." (VERISSIMO, 1987, p. 349)

A intuição de Florêncio se concretizará: Bolívar é o macho que sucumbe diante da teiniaguá sendo lentamente aniquilado, o que se faz notar através de seu físico, devido as transformações que sofre. É Juvenal quem percebe as modificações que 
ocorrem com o sobrinho e, em um diálogo com Winter, observa: “- (...)Ando preocupado com o jeito dele. O Boli envelheceu dez anos depois que casou; anda triste como carancho em tronqueira." (VERISSIMO,1987, p. 405)

Também Bibiana percebe a sedução a que Bolívar foi submetido. É nas constantes modificações de Luzia, ora mostrando-se bondosa, ora fazendo maldades, que encontra a justificativa para o fascínio do filho, impossibilitado de ver "com quem havia casado". Tendo estudado na Corte, ela sabia como conquistá-lo, seduzindo-o com atitudes que o deixavam completamente subjugado: "Bolívar ficava olhando para ela de boca meio aberta e via-se que ele estava perdido de amor, que era capaz de fazer tudo que ela pedisse (VERISSIMO, 1987).

O domínio em posição de destaque no trecho, oportuniza a lembrança da teiniaguá lendária, porque também o sacristão da lenda satisfaz-lhe as vontades, como ocorre no episódio em que ele vai em busca do vinho sagrado, mesmo sabendo que essa atitude significa a transgressão das normas que, até então, norteavam sua conduta ${ }^{5}$. O diálogo intertextual aponta para a possibilidade de Bolívar transgredir. Ele parece estar na iminência de ultrapassar os limites que Bibiana, com tanta firmeza, tenta manter.

Além do caráter dominador/destruidor da personagem, que resulta na degradação física de Bolívar, também o relacionamento sexual indicia traços da devoração. Seguindo a perspectiva de Roger Caillois, que vê nas "dentadas de amor" um traço remanescente, no ser humano, do comportamento da fêmea devoradora, verifica-se que determinadas atitudes de Luzia podem ser analisadas sob este prisma. A arguta Bibiana, sempre atenta ao filho, observa no rapaz "arranhões", "uma mordida" no lábio e "uma queimadura na mão":

“- Contei das malvadezas da... dessa mulher. O senhor já viu como anda a cara do Bolívar? Toda lanhada, toda cheia de arranhões. Um dia amanheceu com os beiços inchados, estava-se vendo que tinha sido uma mordida. Uma pouca vergonha! Ainda ontem descobri uma queimadura na mão do rapaz." (VERISSIMO, 1987, p. 421)

Apesar de não se ter conhecimento das circunstâncias em que essas atitudes tiveram lugar, pelo menos a "mordida" está claramente associada à hipótese de Caillois. De qualquer forma, possivelmente tenham ocorrido durante $\mathrm{o}$ ato erótico, o que permite enquadrá-las como traços co comportamento da "fêmea devoradora".

Apesar de vários elementos contribuírem para apresentar o diálogo intertextual entre a narrativa de Erico Verissimo e a de Simões Lopes Neto, está no caráter sedutor/devorador das duas personagens a principal aproximação entre elas. Os demais aspectos apenas confirmam o diálogo e possibilitam a análise de Luzia à luz da teiniaguá lendária. É justamente o seu poder de sedução sobre o macho, que se sente indefeso a sua frente, dominado pelo seu fascínio, que, ao indiciar a subversão da ordem, permi-

${ }^{5} \mathrm{O}$ sacristão da lenda, desde o início, é advertido pelos padres contra a teiniaguá. O episódio do vinho significa a efetiva contradição aos princípios religiosos. Também Luzia não está em consonância com os ditames da religião. Esta situação aclara-se no diálogo que tem com Pe. Otero, quando põe em xeque a existência da alma: “- Vosmecê tem certeza de que eu tenho uma alma?' (VERISSIMO,1987, p. 525) um dos dogmas do catolicismo. 
te o enfoque da personagem sob um prisma negativo. São, pois, as relações intertextuais que oportunizam interpretações mais abrangentes da personagem: é apenas no seu confronto com a teiniaguá lendária que se passa a atentar para o caráter devorador de sua sexualidade e se entende o fato de ser vista como louca pelos santa-fezenses, porque, ao diferenciar-se das outras mulheres, representa o desvio da norma, daí o temor que acarreta nos homens, que fogem ao seu convívio. O fascínio que exerce sobre Bolívar, do qual ele não consegue fugir, é determinante de sua morte. Está, pois, neste caráter devorador/destruidor o fator determinante de sua ruína.

\section{BIBLIOGRAFIA}

BAUDRILLARD, Jean. Da sedução. Campinas/SP, Papirus, 1991.

BOSI, Alfredo. Fenomenologia do olhar. In: NOVAES, Adauto et alii. O olhar. São Paulo, Companhia das Letras, 1988.

CAILLOIS, Roger. O mito e o homem. Lisboa, Edições 70, 1972.

CAMPBELL, Joseph, com Moyers. O poder do mito. São Paulo, Palas Athena, 1990.

CHAVES, Flávio Loureiro. Erico Verissimo: realismo \& literatura. Porto Alegre, Mercado Aberto, 1981.

CHAVES, Flávio Loureiro. Simões Lopes Neto: regionalismo \& literatura. Porto Alegre, Mercado Aberto, 1982.

CHEVALIER, Jean, GHEERBRANT, Alain. Dicionário de símbolos. Rio de Janeiro, José Olympio, 1989.

HOMERO. Odisséia. São Paulo, Abril Cultural, 1979.

LOPES NETO, Simões. Contos gauchescos e lendas do sul. Porto Alegre, Globo, 1978.

MEYER, Augusto. Textos críticos. São Paulo, Perspectiva; Brasília, INL?Fundação Nacional Pró-Memória, 1986.

SCHÜLER, Donaldo. O tempo em $O$ continente. In: CHAVES, Flávio Loureiro et alii. O contador de histórias: 40 anos da vida literária de Erico Verissimo. Porto Alegre, Globo, 1972

VERISSIMO, Erico. O tempo e o vento. O continente. Rio de Janeiro, Globo,

1987. 